\title{
A Proposed Model For IMPROVING Performance ANd Reducing Costs Of It Through Cloud Computing Of Egyptian BUSINESS ENTERPRISES
}

\author{
Prof. Mohamed M. El Hadi ${ }^{1}$ and Azza Monir Ismail ${ }^{2}$ \\ ${ }^{1}$ Department of Computer \& Information Systems, Sadat Academy, Cairo, Egypt \\ 2 MSc. Candidate of Computers \& Information Systems, Sadat Academy, Cairo, Egypt
}

\begin{abstract}
Information technologies are affecting the big business enterprises of todays from data processing and transactions to achieve the goals efficiently and effectively, affecting creates new business opportunities and towards new competitive advantage, service must be enough to match the recent trends of IT such as cloud computing. Cloud computing technology has provided all IT services. Therefore, cloud computing offers an alternative to adaptable with technology model current, creating reducing cost (Fixed costs and ongoing), the proliferation of high speed Internet connections through Rent, not acquisitions, cheaper powerful computing technology and effective performance. The public and private clouds are characterized by flexibility, operational efficiency that reduces costs improve performance. Also cloud computing generates business creativity and innovation resulted from collaborative ideas of users; presents cloud infrastructure and services; paving new markets; offering security in public and private clouds; and providing environmental impact regarding utilizing green energy technology. In this paper, the main concentrate the cloud computing.
\end{abstract}

\section{KEYWORDS}

Cloud Computing, Public Clouds, Private Clouds, IT, Reduce Costs, Improve Performance, Green Energy.

\section{INTRODUCTION}

Cloud computing technology has importance in the business enterprise, it has grown in recent years due to the advantages of greater i.e. usability and availability of computing resources at lower cost. Not by owning them, but as a service by rent (monthly, weekly). It could be considered that cloud computing is a kind of computing where, IT capabilities are provided as service to multiple end users through the internet. Therefore, it leads to improve performance and reducing costs in the company $[1,2]$.

In this paper, we introduce the main aspects related to concepts, essential characteristics, types of cloud computing. It presents an attempt to Proposed the model of cloud computing for the company and finally the conclusions. 


\section{Features Of Cloud Computing}

The aim of this part is to introduce the features of cloud computing as follows:

\subsection{The Definition Of Cloud Computing}

"Clouds are a large pool of easily usable and accessible virtualized resources (such as hardware, development platforms and/or services). These resources can be dynamically reconfigured to adjust to a variable load (scale), allowing also for an optimum resource utilization. This pool of resources is typically exploited by a pay-per-use model in which guarantees are offered by the Infrastructure Provider by means of customized service level agreements (SLAs) [6, 20]. The Figure: 1 explains cloud definition from NIST [7].

\section{Cloud Definition from NIST}

\section{Visual Model of NIST's Working Definition of Cloud Computing}

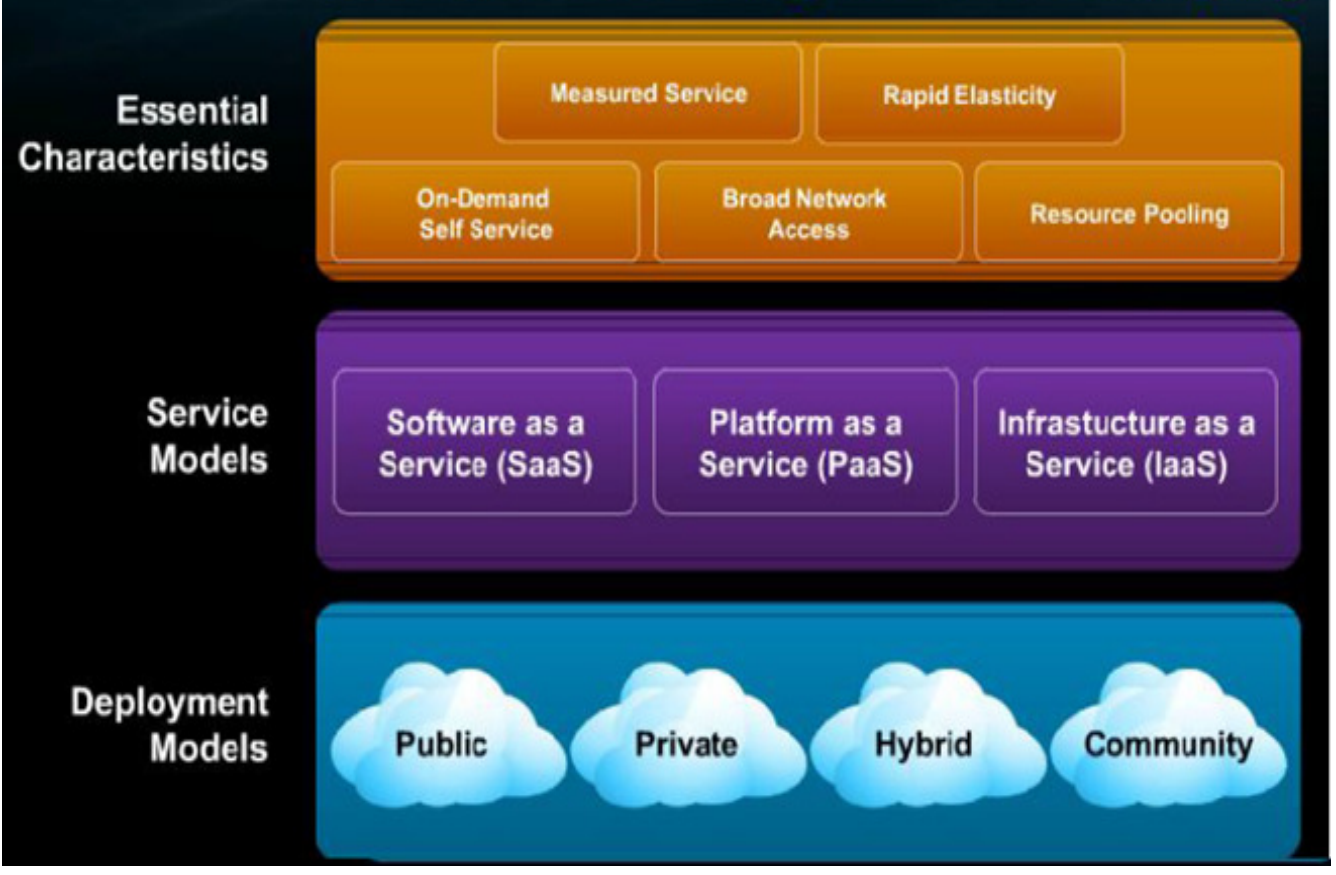

Figure 1. Cloud Definition from NIST.

When analyzing the concepts available for cloud computing, it can be concluded that they correspond to the key points which are as following [2]:

- Confirms the arrival of cloud computing on demand to computing resources warehouse available to business enterprises.

- Providing services, dynamic and scalable to business enterprises for information technology. 
- Lead to the independence of the machines and separate them from the means available.

- Contributes to the maintenance easier for an application, there is no need to install or download on the computers of users [2]:.

After a thorough review of existing cloud computing definitions and analyzing the concepts available for cloud computing so the cloud computing can be defined in this paper as the following "Cloud is the combination of both applications delivered as services over the internet, and data centers hardware and software that provide those services, and the users can use those services by on-demand service model and a "pay as you go" payment method where the users use the service when they need it and pay only for what they used of computing resources , also users can access everything on the cloud by PC's, Laptops, Smart phone also can be rapidly provisioned and released with minimal management effort or service provider interaction, cost reduction, improve performance"

\section{Performance Of Cloud Computing}

The main source of performance problems comes from the connection quality between the user and the cloud computing server, mainly when more users are connecting at the same time and large amounts of data are transferred between the end user and the cloud server. This results in a slowdown in the cloud service. Performance measures ought to relate to the goals and objectives of the organization. Performance measurements should be: valid, reliable, understandable, timely, consistent, sensitive to data collection costs and non redundant [11].

The performance issue is an important factor which companies have to think implement cloud computing. Companies should measure their possible current and future bandwidth and processing requirements before they decide to implement cloud computing. Performance is seeing an important opportunity for organizations. [14].

\section{Cost Reduction Of Cloud Computing}

The cost is an important thing about the companies before switching to cloud computing Reduction in cost is also a primary factor for an inclination toward cloud computing. The companies have to spend a lot of cost for setting up IT infrastructure and remains the resources (hardware, software and network) cannot be fully utilized which is a waste of money. But by using cloud an organization has to pay for the resources they will use (pay using only). Reduction in cost and improving performance depends upon the cloud deployment model on internet. [15, 20].

\section{Proposed Model For Cloud Computing Of Egyption Business ENTERPRISES}

The components of the model for cloud computing Of Egyption business enterprises as follows (as shown in figure: 2 ): 


\subsection{INFrastructure As A SERVICE LAYER}

IaaS layer is the basis to provide high-level services. It provides virtual hardware resources ( such as memory capacity or processing power.) on demand for the end users [26].

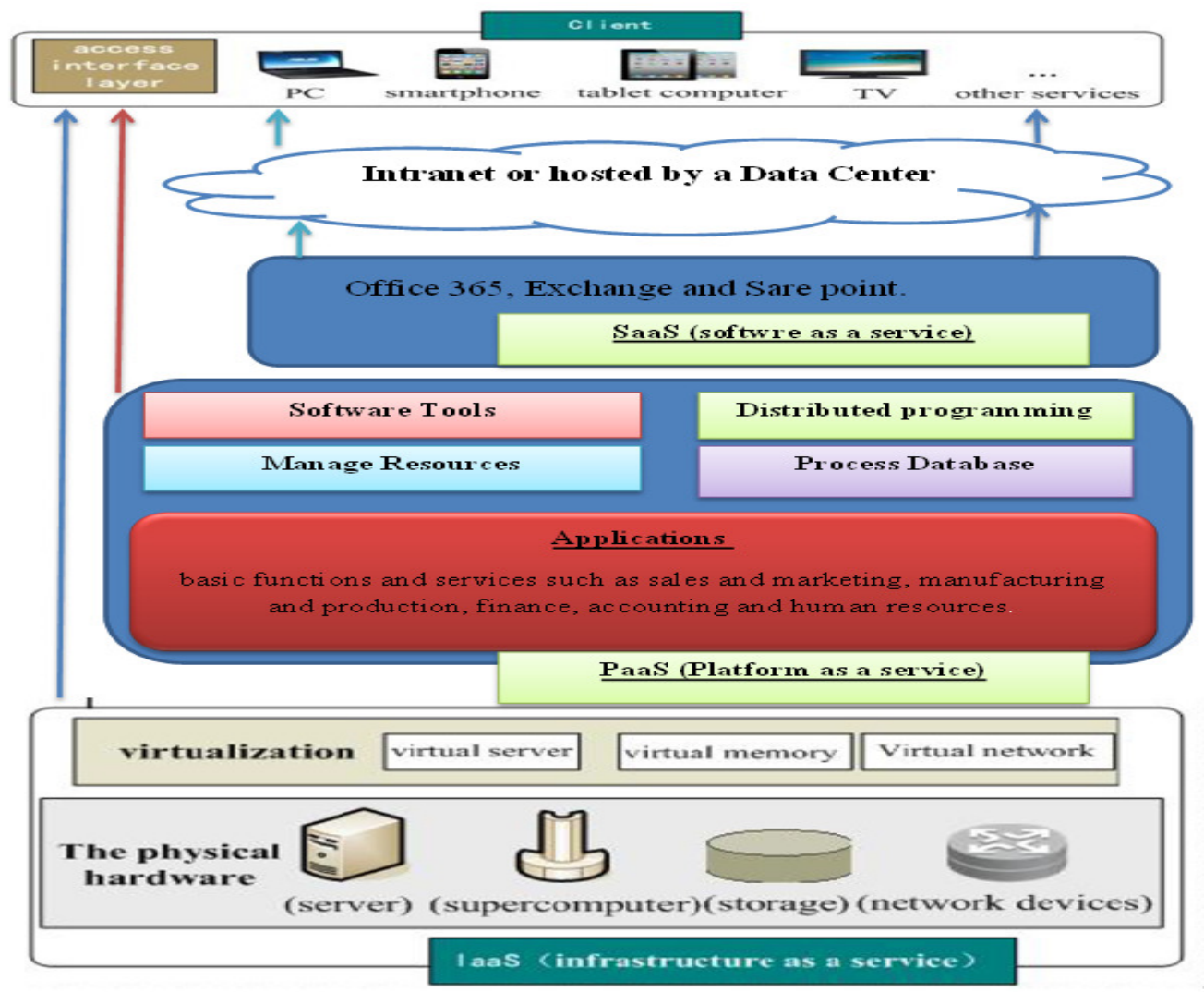

Figure 2. The Proposed Model of Cloud Computing.

\subsubsection{VIRTUALIZATION}

These capabilities can be utilized by the automation, and orchestration layers to manage the virtualization layer. [27].

\subsection{Platform As A Service Layer}

PaaS layer is mainly to study the massive data processing technology, resource management, etc. Via the software tools of PaaS layer, when utilizing services, the application developers only need to upload the program code and data rather than pay much attention to the management problems of the underlying network, storage, and operating system.

To deploy applications. IT can deliver new capacity to meet business needs without requiring a capital investment to acquire a new infrastructure each time. Platform as a service Layer will govern all the processes, mechanisms and procedures used to store and access data in the Cloud System such as SQL server Database. The SQL Database service enables organizations to rapidly create, scale and extend applications into the cloud with familiar tools such as windows server 2012 [27]. 


\subsection{Software As A SERVice LaYer}

Software as a service layer provides the Internet-based software application services. SaaS layer transfers the desktop application programs to the Internet, which is capable of achieving to access everywhere of the application programs therefore it is Facing the end-users of cloud computing Software as a service layer such as office 365 , exchange and share point.

\subsection{Client Layer}

The Client layer is directly oriented to users to manipulate data and information. Information technology functions Distributed on the main activities of the company, includes sales and marketing, manufacturing and production, finance and accounting and human resources [27].

\section{Conclusions}

Cloud computing technology is becoming recently a widespread domain of Information Technology field that is geared to cover various applications for use across business enterprises and industry areas to help increase knowledge of what is possible from sales and marketing customers and contact or data centers, supply chain of products and services, financial, human resources to specific areas across business analytics, business intelligence, business process management, location intelligence, operational intelligence, information and data to business focused collaboration.

\section{ACKNOWLEDGEMENTS}

The authors would like to thank everyone at, Sadat Academy, Cairo, Egypt

\section{REFERENCES}

[1] V. Krishna Reddy, B. \& P.Sai Kiran (July 2011) "Research Issues in Cloud Computing " Global Journal of Computer Science and Technology, Vol. 11, No 11.

[2] El Hadi, Mohamed M..( May 2012). "Towards Design of a Preliminary Model for the Application of Cloud Computing in Educational Institutions". Proceedings of the 19th Scientific Conference for Information Systems and Computer Technology, Cairo: Sadat Academy-Faculty of Management Sciences (Higher Studies)

[3] W. Jansen and T. Grance, "Guidelines on Security and Privacy in Public Cloud Computing" Retrieved (January 2011), available at: https://cloudsecurityalliance.org/wpcontent/uploads/2011/07/NIST-Draft-SP-800-144_cloud-computing.pdf

[4] Mladen,A. "Cloud Computing-Issues, Research and Implementations". Retrieved May 2008, available http://hrcak.srce.hr/search/?q=Cloud+Computing+\%E2\%80\%93+Issues\%2C+Research+and+Implem entations.

[5] Jäätmaa, Jaakko. "Financial Aspects of Cloud Computing Business Models" Retrieved January 2010, available at: http://epub.lib.aalto.fi/fi/ethesis/pdf/12435/hse_ethesis_12435.pdf

[6] Etro, Federico. "The Economics of Cloud Computing". The IUP Journal of Managerial Economics. Vol. IX, No. 2, March 2011., available at:http://www.intertic.org/Policy\%20Papers/JManEc.pdf.

[7] Mell, Peter. and Grance, Tim. "The NIST Definition of Cloud Computing" , (2009), available at: http://www.nist.gov/itl/cloud/upload/cloud-def-v15.pdf.

[8] SUPPORT, RACKSPACE. "UNDERSTANDING THE CLOUD COMPUTING STACK: SAAS, PAAS, $\quad " \quad$ IAAS 2013, AVAILABLE HTTP://WWW.RACKSPACE.COM/KNOWLEDGE_CENTER/WHITEPAPER/UNDERSTANDIN G-THE-CLOUD-COMPUTING-STACK-SAAS-PAAS-IAAS 
[9] Huth, Alexa. and Cebula, James. "The Basics of Cloud Computing”, 2011, available at: [https://www.us-cert.gov/sites/default/files/publications/CloudComputingHuthCebula.pdf]

[10] Furht, Borko. and Escalante, Armando. eds. (2010). "Handbook of Cloud Computing". New York: Springer, pp.3-18.

[11] Chapter, Colorado. "Benchmarking, Best Practices, and Performance Measurements for Public Entity Risk Management. Maryland: Public Entity Risk Institute“, pp.23-24, November 1999 available at: http://www.riskinstitute.org/peri/images/file/Benchmarking_Guidelines.pdf

[12] Singh, Gurdev., Sood, Shanu. and Sharma, Amit. "CM - Measurement Facets for Cloud Performance. “ International Journal of Computer Applications . Vol.23, No. 3, pp.1-6, June 2011. http://www.ijcaonline.org/volume23/number3/pxc3873714.pdf

[15] Mansour, Jameel, Ahmed. "The Adoption of Cloud Computing Technology in Higher Education Institutions: Concerns and Challenges (Case Study on Islamic University of Gaza "IUG"“, pp.39-40, 2013. available at: http://library.iugaza.edu.ps/thesis/109990.pdf

[16] Garg, Kumar, Saurabh., Versteeg, Steve. and Buyya, Rajkumar. "A Framework for Ranking of Cloud Computing Services”. Future Generation Computer Systems - Journal - Elsevier. No. 29, pp.10131016, 2013. available at: http://www.cloudbus.org/papers/RankingClouds-FGCS.pdf.

[17] B. Sotomayor, et al, "Virtual Infrastructure Management in Private and Hybrid Clouds," IEEE Internet Computing, Sept. 2009.

[18] J. Viega and McAffee, "Cloud Computing and the Common Man," Published by the IEEE Computer Society. 2009.

[19] C. Hoffa, et al., "On the Use of Cloud Computing for Scientific Workflows," IEEE Fourth Int'l Conf. One Science, Dec. 2008.

[20] What is Cloud Computing? Retrieved April 6, 2011, available at: http://www.microsoft.com/business/engb/solutions/Pa ges/Cloud.aspx

[21] Sugam Sharma, U S Tim, Shashi Gadia, and Johnny Wong.(2015).Proliferating Cloud Density through Big Data Ecosystem, Novel XCLOUDX Classification and Emergence of as-a-Service Era.(http://www.public.iastate.edu/ sugamsha/articles/Cloud\%20Density\%20in\%20Big\%20Data\%20 Ecosystem,\%20Nove1\%20XCLOUDX\%20Classification\%20and\%20Emergence\%20of\%20aaS\%206 $\% 2014 \% 202015 . p d f)$

[22] Sugam Sharma. (2015). Evolution of as-a-Service Era in Cloud. Cornell University Library.(http://arxiv.org/ftp/arxiv/papers/1507/1507.00939.pdf)

[23] Sugam Sharma, U S Tim, Shashi Gadia, and Johnny Wong.(2015).Growing Cloud Density \& as-aService Modality and OTH-Cloud Classification in IOT Era. (http://web.cs.iastate.edu/ sugamsha/articles/Growing\%20Cloud\%20Density\%20\&\%20as-aService\%20Modality\%20and\%20OTH-CLOUD\%20Class\%20-\%20R1\%2011.pdf)

[24] J.W Rittinghouse and J.F. Ransome, "cloud computing implementation, management and security", CRC press Taylor \& Francis Group 2009.

[25] Bertram, Dane. "Likert Scales”, p.2, 2006. available at: http://poincare.matf.bg.ac.rs/ kristina/topicdane-likert.pdf.

[26] Hui Zhou, Hong Zeng and Shigang Qín, “Application Research of Cloud-based Education Network Platform", $\quad$ p.3, $\quad 2014 . \quad$ available http://iaesjournal.com/online/index.php/TELKOMNIKA/article/view/4382/2742.

[27] FlexPod with Microsoft Private Cloud - Architecture Overview, 2012, available at: http://www.cisco.com/c/dam/en/us/solutions/collateral/data-center-virtualization/microsoftapplications-on-ucs/ucs_flexpod_ms_netapp.pdf

[28] Factors Affecting Adupting of Cloud Computing Technology in Technical education., 2015, available at: http://www.slideshare.net/ajer123/factors-affecting-adoption-of-cloud-computing-technology-intechnical-educations-a-case-study-of-technical-institution-in-meerut-city.

[29] Agnieszka Sawa, Slawomir Sklinda "Capital Asset Pricing Model and Arbitrage Pricing Theory" ", p.78, 2003. available at: http://pure.au.dk/portal-asb-student/files/2370/000125056-125056.pdf 


\section{AUTHORS}

Prof. Mohamed El Hadi (PhD '64) who studied at The University of Illinois Graduate School of Library and Information Science (GSLIS). He already an emeritus professor of Information Systems at Sadat Academy for Management Sciences in Egypt as well as the president and founder of the Egyptian Society for Information Systems and Computer Technology (ESISACT) which recently organized its 19th Scientific Conference on "Towards Cloud Computing Technology to Enable Egyptian Business Enterprise to Maximize Their IT Resources", as well as the other previous 18 conferences." He Advisor was the late Dr. Harold Lancour (director of the library school) during the period 1958-1960; Ph.D. Advisor was the late Dr. Robert B. Downs (the dean of the library school and the university libraries) during the period 1961 - 1964. He worked as an assistant to Dr. Goldstein, and afterwards he worked as an assistant in the Library Cataloging Department."

Azza Monir Ismail : MSc. Candidate of Computers \& Information Systems, Sadat Academy, Cairo, Egypt 